\title{
Spontaneous regression of solid-pseudopapillary neoplasms with hepatic metastases
}

\section{Xiaocheng Li, Yahui Liu}

Department of Hepatobiliary and Pancreatic Surgery, the First Hospital of Jilin University, Changchun, China

Correspondence to: Yahui Liu, MD. The First Hospital of Jilin University, No. 71 Xinmin Street, Changchun, China. Email: yahui@jlu.edu.cn.

Submitted Oct 20, 2021. Accepted for publication Dec 15, 2021.

doi: $10.21037 / \mathrm{hbsn}-21-438$

View this article at: https://dx.doi.org/10.21037/hbsn-21-438
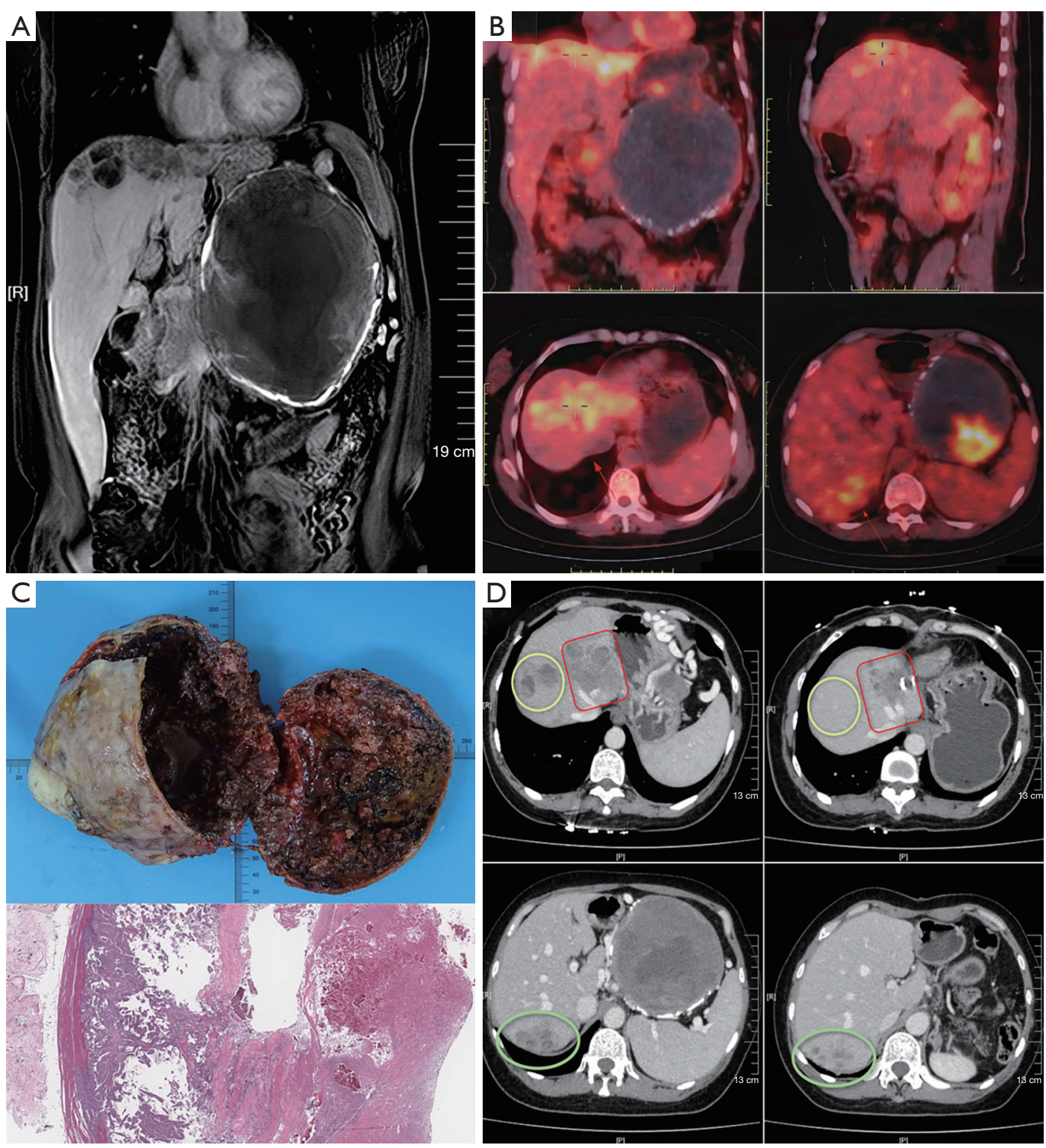
A 42-year-old female patient was presented to our hospital due to abdominal distension for 3 weeks. MRI scan showed a huge mass (16 $\mathrm{cm}$ diameter) in the pancreatic tail and irregular low-density shadows $(0.4-5.6 \mathrm{~cm}$ diameter) in the liver with left outer lobe atrophy (Panel A). These lesions have increased radioactive uptake in PET/CT (Panel B). The patient underwent distal pancreatectomy, splenectomy, left lateral hepatectomy and pathological examination confirmed the diagnosis of solid-pseudopapillary neoplasms (Panel C; staining method HE, magnification $\times 20$ ).

The remaining liver metastases were not treated postoperation. At 20 months follow-up, enhanced CT of the abdomen showed shrinkage and disappearance of the liver metastases, with no further distant metastatic disease (Panel D). Spontaneous regression of the hepatic metastases may be attributed to primary tumor resection tipping the immune-mediated balance towards the host, enabling or stimulating the immune system to control residual disease. However, the pathophysiological basis of this phenomenon remains to be investigated.

\section{Acknowledgments}

Funding: This study was financially supported by the Specific Project for Medical and Health Talent of Jilin Province (Grant No. JLSCZD2019-021).

Cite this article as: Li X, Liu Y. Spontaneous regression of solid-pseudopapillary neoplasms with hepatic metastases. HepatoBiliary Surg Nutr 2022;11(1):169-170. doi: 10.21037/ hbsn-21-438

\section{Footnote}

Provenance and Peer Review: This article was a standard submission to the journal. The article has undergone external peer review.

Conflicts of Interest: Both authors have completed the ICMJE uniform disclosure form (available at https://hbsn. amegroups.com/article/view/10.21037/hbsn-21-438/coif). The authors have no conflicts of interest to declare.

Ethical Statement: The authors are accountable for all aspects of the work in ensuring that questions related to the accuracy or integrity of any part of the work are appropriately investigated and resolved. Written informed consent was obtained from the patient for publication of this manuscript and any accompanying images.

Open Access Statement: This is an Open Access article distributed in accordance with the Creative Commons Attribution-NonCommercial-NoDerivs 4.0 International License (CC BY-NC-ND 4.0), which permits the noncommercial replication and distribution of the article with the strict proviso that no changes or edits are made and the original work is properly cited (including links to both the formal publication through the relevant DOI and the license). See: https://creativecommons.org/licenses/by-nc-nd/4.0/. 